\title{
Using airpuffs to elicit the human blink reflex
}

\author{
PAUL HAERICH \\ Loma Linda University, Loma Linda, Califomia
}

\begin{abstract}
The startle response-- a reflex organized at the level of the brainstem--has gained increased popularity during the past 20 years among psychophysiologists as both an investigative tool and an object of exploration in its own right. This article describes a method for eliciting the reflex eyeblink using a puff of air; the equipment and its operation are described. Airpuff-elicited reflexes are proposed as an informative adjunct to acoustic, photic, and electrocutaneous blink reflexes, particularly for some very young and aged subject populations.
\end{abstract}

The startle response is a reflex that is organized at the level of the brainstem. It has gained increased popularity during the past 20 years among psychophysiologists as both an investigative tool and an object of exploration in its own right. A search of the PsycLIT database from 1974 through 1995 using startle, prepulse inhibition, and blink reflex as search terms demonstrates this growth of interest; inspection of the results of this search reveals that the number of articles published each year in this area grew from approximately 25 in the late 1970 s to nearly 100 in 1995 , with much of the increase occurring in the last decade.

Despite this recent proliferation of studies, the use of airpuff-elicited blink reflexes as a dependent measure has a long history in experimental psychology. Much of the earliest work was done by Ernest Hilgard (Hilgard, 1931; Hilgard \& Campbell, 1936; Hilgard \& Marquis, 1935, 1936), who investigated the conditioning of the reflex across species from dogs to monkeys to humans. This tradition continued through the "Golden Age of Behaviorism" (e.g., Spence, 1966; Spence \& Ross, 1959) to the present, where recent work has been useful in describing the neural bases of classical conditioning of the eye blink in the rabbit brainstem (Krupa, J. K. Thompson, \& R. F. Thompson, 1993; R. F. Thompson, 1986) and in humans (e.g., Daum et al., 1993; Woodruff-Pak, Romano, \& Papka, 1996).

Among these studies of basic reflex mechanisms, conditioning, and habituation (inter alia), the startle reflex, of which the reflex blink is the most robust component (Landis \& Hunt, 1939), has emerged during the past two decades as a useful tool in two broad areas of investigation. In one, startle response techniques have been applied to the area of emotion where the magnitude of the reflex (not just its presence or absence as in the classical conditioning

This manuscript was developed from a presentation at the $32 \mathrm{nd}$ Annual Meeting of the Society for Psychophysiological Research in Toronto, October 1995. The author thanks Scott Vrana and an anonymous reviewer for their helpful comments on an earlier draft of this manuscript. Correspondence should be addressed to P. Haerich, Psychophysiology \& Human Cognition Laboratory, Department of Psychology, The Graduate School, Loma Linda University, Loma Linda, CA 92350 (e-mail: phaerich@ccmail.llu.edu). paradigm) is facilitated by a state of negatively valent affect (Haerich, 1994; Lang, Bradley, \& Cuthbert, 1990, 1992; Vrana, Spence, \& Lang, 1988). A second, earlier line of research may be traced to Frances Graham's influential publication on prepulse modification (Graham, 1975); these studies employ the startle response to investigate selective attention, since the magnitude of the reflex has been demonstrated to vary directly with the allocation of attentional resources (Anthony \& Graham, 1983; Hackley \& Graham 1987; Haerich, 1994). This work on selective attention exploits one of the useful aspects of startle response-that the reflex may be elicited via multiple stimulus modalities (e.g., with acoustic, visual, and cutaneous stimuli), providing the opportunity for attention to be variously directed to stimuli in modalities that may then match or mismatch that through which the startle is elicited.

The fundamental requirement for elicitation of the startle response is an abrupt increase in stimulus intensity (Anthony, 1985; K. M. Berg, 1973). This may be accomplished with acoustic stimuli using either pure tones or white noise (e.g., Anthony \& Graham, 1983; K. M. Berg, 1973; Haerich, 1994). Flashes of light from strobe lamps or flash guns have provided the visual stimuli used to elicit the photic blink reflex (Hackley \& Johnson, 1996; Witvliet \& Vrana, 1996). Electrical stimulation of the supraorbital nerve has often been used as a cutaneous stimulus (Boelhouwer, Teurlings, \& Brunia, 1991; Brunia \& Boelhouwer, 1988).

An alternative method of eliciting the blink reflex with a tactile stimulus is the use of an airpuff (Hackley \& Graham, 1983; Haerich, 1994). In comparison with electrocutaneous stimuli, airpuff stimuli are similarly effective in that response probability approaches 1.0 ; moreover, given the recent focus on modulation of the blink reflex by emotional stimuli, an airpuff stimulus (as long as it is not directed, or perceived as being directed, into the subject's eye; see Haerich, 1994) has the advantage of not having the "built-in" anxiogenic properties of an electric shock.

Among the other potential benefits of this approach is that it allows investigations to be conducted with human populations, for which high-intensity acoustic stimuli may not be advisable. For example, with infants and young 
children one might wish to avoid repeated exposure to high-intensity acoustic stimuli because of their particular sensitivity to stimuli composed of high frequencies (American Academy of Pediatrics Committee on Environmental Health, 1994). Moreover, in studies with elderly people, the ability to use a cutaneous stimulus would enable the experimenter to avoid the complications produced by presbycusis.

Taken together, the increase in the use of the human startle response in psychophysiological research and the utility of airpuffs as tactile stimuli to elicit this reflex suggest that it would be worthwhile to provide information about the construction of a system for generating these stimuli with more detail than is usually provided in a method section. The purpose of this paper, then, is to describe a method by which airpuffs may be used to elicit the blink reflex. First, I will describe the equipment necessary to present an airpuff stimulus to elicit the blink reflex using the system in my laboratory at Loma Linda University (LLU) as an example. I will present information on the operation and quantification of the system and stimulus. Finally, I will discuss some of the potential problems that might arise in the instantiation and implementation of an airpuff system and some tentative solutions.

\section{Equipment}

To present an airpuff stimulus, an investigator needs (1) an air source, (2) some means of delivering the air to the desired location, and (3) some means of controlling the presentation of the puff (i.e., when and for how long). A flow diagram illustrating the components and their assembly in the LLU system is provided in Figure 1.

In early work reported by Hilgard (e.g., Hilgard \& Marquis, 1935), a rubber bulb was used to create manually a supply of compressed air behind an electronically triggered stopcock on each trial. A nonmanual variant of this approach, employed by a number of investigators (Hackley \& Graham, 1983, 1987; Woodruff-Pak et al., 1996), uses an air compressor with its own refillable reservoir as the source of air. Air compressors are not prohibitively expensive and are available at many hardware stores. Another alternative for a source of air that is also both economical and readily obtainable is a reusable tank of compressed oxygen. The LLU system uses a standard $275-\mathrm{ft}^{3}$ tank of compressed $\mathrm{O}^{2}$, which is obtained from the University's Physical Plant Maintenance Department (a local welding supply company has also been used in the past). A single tank has been sufficient to present from 60 to 100 airpuffs to each of over 200 subjects before needing to be refilled. ${ }^{1}$ Both purified (i.e., for hospital use) and industrial grade $\mathrm{O}^{2}$ (sometimes referred to as industrial air) are available, with the latter being less expensive. Finally, an alternative to a large tank of industrial air is a scuba tank, which may also be readily refilled (although a diving license or equivalent certification is required at reputable dive shops in North America).

The flow of compressed air from the tank must be controlled by a regulator. This is necessary because the pres-

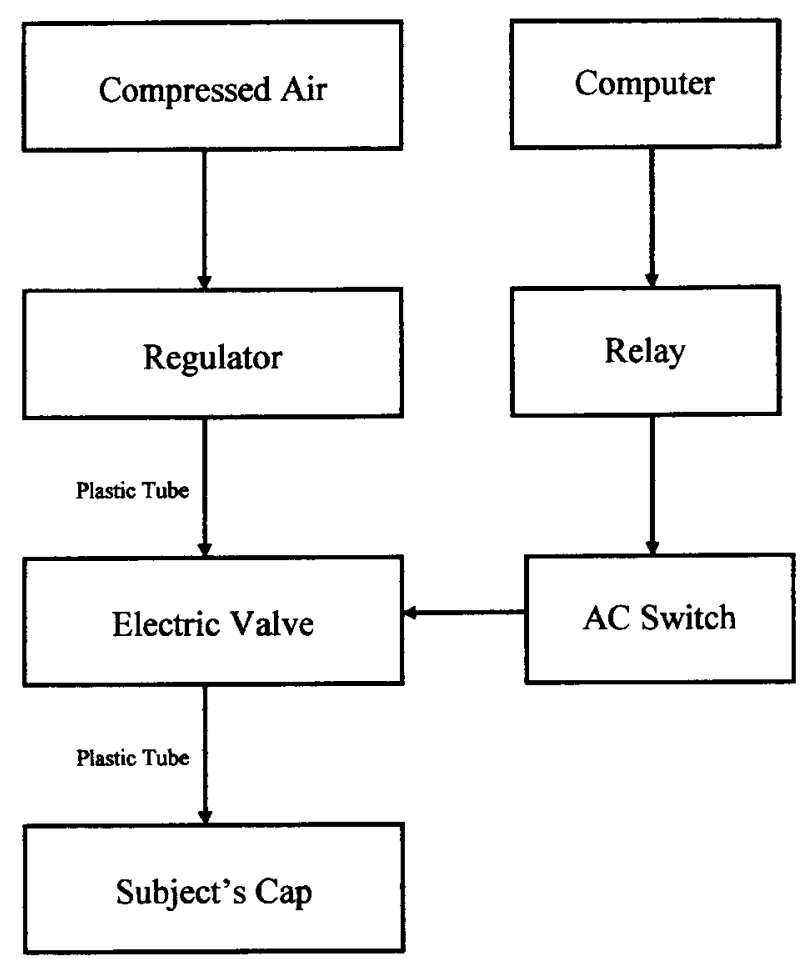

Figure 1. A flow diagram of the equipment and control used to present airpuffs to elicit the reflex blink.

sure of air in a full tank may be greater than $13000 \mathrm{kPa}$, whereas the desired pressure for blink elicitation is about 5-25 kPa. Because of the large differential between the tank and outflow pressures, a two-stage regulator is recommended to increase the precision and stability of the stimulus pressure. Moreover, it is also important to remember, when selecting a regulator, that the size and type of connector will vary depending on the tank (e.g., a CGA 540 connector is used with $\mathrm{O}_{2}$ ); thus, it is important to match the regulator and the tank. Finally, selecting a regulator where the maximum outflow pressure is less than about $200 \mathrm{kPa}$ or $30 \mathrm{psi}$ will help to provide sufficient sensitivity in setting the stimulus intensity. Regulators may be purchased from instrument supply companies, such as Fisher Scientific (which currently lists two-stage brass regulators at about $\$ 200$ ).

In the LLU system, air flows from the regulator through a plastic tube (inner diameter $4 \mathrm{~mm}$, or $5 / 16 \mathrm{in}$.) and is then presented to the side of the subject's face to elicit the reflex. The challenge in stimulus presentation is to maintain a consistent presentation location. One way this may be done is by constructing an apparatus that includes a frame for chin and forehead rests with the tube attached to this frame so that the relationship between the subject's head and the opening of the tube is constant. Even so, from trial to trial, there are likely to be variations between the subject's head location and the plastic tube. To avoid this, a better approach is to fix the air tube to a cap that the subject wears. This allows head movements by the subject, 
while maintaining the constant placement of the airpuff. In the LLU system, the plastic tube is fixed to the bill of a baseball-style cap; two flexible metal strips are bolted to the bill of the cap with the plastic tube secured in place between them. One strip extends $7-9 \mathrm{~cm}$ beyond the left edge of the bill and, with the end of the plastic tube attached, acts as a guide that can be manually adjusted for each subject such that the location of the airpuff is maintained across subjects. Using a soft, baseball-style cap, as opposed to, say, a hard hat or helmet, enables the subject to wear a pair of headphones. As will be discussed below, low-intensity white noise presented through headphones eliminates or significantly reduces the effects of acoustic artifacts often associated with airpuff stimuli.

Finally, in order to start and stop the flow of air through the tube to the subject, an electric solenoid controlled valve is placed in the line between the regulator and the subject (Figure 1). The one in the LLU system was manufactured by Skinner Electric Valves (New Briton, CT); this company is now a division of Honeywell Inc., and the equivalent solenoid valve is currently part of their 7000 series. The valve is operated by an ac switch output (Coulbourn Instruments, S63-01), which is, in turn, operated by a computer-controlled relay. ${ }^{2}$

\section{Operation}

The most frequently used stimuli to elicit the startle eyeblink are acoustic. When the reflex is elicited with acoustic stimuli, the parameters that are important to control and report include the stimulus intensity, its rise/fall time and duration, the frequency composition of the stimulus (i.e., pure tones vs. white noise), and the mode of presentation (i.e., free field vs. headphones, monaural vs. binaural). Each of these parameters has been demonstrated to have an effect on the amplitude, latency, or probability of a response (K. M. Berg, 1973; Blumenthal \& W. K. Berg, 1986a, 1986b). On a conceptual level, similar parameters for airpuff stimuli would include the outflow air pressure, the movement latency and duration of the solenoid's opening and the delay for the airpuff to reach the end of the plastic tube, the type of gas used, and the mode of presentation (i.e., where on the face the airpuff is presented). Each of these parameters is discussed below.

Stimulus timing. When reporting the presentation of an acoustic stimulus, an investigator typically need not consider more than the timing of the commands by the computer. That is, the latency between the computer's signal to close an electronic switch allowing current to flow to a speaker or headphone and the subsequent generation of an auditory stimulus by the speaker or headphone is negligible. The only noticeable delay might be if the stimulus was delivered in a free-field setting through a standing speaker with the subject at a distance of multiple meters from the sound source. In this case, the latency between the air pressure wave being generated by the speaker and its reaching the subject's ear would need to be taken into account. When working with an airpuff, the delay from the computer command to present the stimulus release of air from the tube is inherent in the equipment. An air pressure pulse is generated at the opening of the valve, and some time is required for the pressure wave to travel down the tube to the subject. This delay will depend on the inertia of the solenoid (i.e., the time between the electronic command for the valve to open and when it is actually open) and on the distance (the length of the tube) from the solenoid to the subject, and it will be constant for the apparatus. ${ }^{3}$ These delays must be taken into account when considering the actual timing of stimulus presentations.

A simple method for measuring the delay is to place a microphone at the same location as the subject in relation to the plastic tube and to direct the flow of air across it. The output of the microphone may then be routed into an oscilloscope or a channel of the polygraph as though it were a physiological signal. The movement of air from the airpuff across the microphone will cause a voltage "response," and the onset of this activity may be measured to indicate the arrival the airpuff at the skin. In the LLU system, this delay is $28 \mathrm{msec}$. This measurement of the stimulus onset timing may be incorporated into the data collection process by placing a Y-connector between the solenoid valve and the subject, running one output to the subject as described and the other output to a microphone, providing a trial-by-trial measurement of the stimulus timing (Hackley \& Graham, 1987).

Finally, there is one additional source of timing variance. The ac switch operates with the phase of the alternating current. With a $60-\mathrm{Hz}$ ac system, this introduces a \pm 4 -msec uncertainty into the timing of the solenoid. Given a sufficient number of trials, this uncertainty may be regarded as essentially random noise. However, if the trials per condition are few, some significant uncertainty as to stimulus timing will remain.

Air pressure and stimulus intensity. The intensity of the stimulus is represented by the force of the air molecules striking the skin's surface. The intensity of a flowing fluid is described in terms of pressure, with pressure defined as the amount of force per unit area. However, providing the pressure of the system between the regulator and the closed solenoid valve does not sufficiently describe the effective intensity of the airpuff. In a closed system, such as exists before the solenoid valve has opened, the pressure is equal throughout. However, when the air is flowing, the rate of flow changes with the radius of the tube. Changes in the radius of the tube (e.g., between the regulator or solenoid valve and the tubing, or from one size tubing to another) produce changes in the flow or velocity of the air; if one is interested, these changes may be calculated with Poiseuille's law. Because a change in velocity is definitional for acceleration and force is the product of mass and acceleration, the effective intensity of the airpuff depends on the size of the tube through which the air is flowing. Furthermore, once the airpuff exits the tubing, the pressure will decrease at a rate inversely proportional to the square of distance from the 
orifice (i.e., the inverse square law). The bottom line for all of this is that, while rates of flow, airpuff force at the skin, and other values may be calculated, the effective intensity of the airpuff stimulus is dependent on three parameters that are easily determined and reported: (1) the outflow pressure from the regulator that may be recorded from the gauge on the regulator itself, (2) the diameter of the plastic tube's orifice through which the airpuff is presented to the subject, and (3) the distance of the opening from the skin. These three parameters should be reported in the method section; together, they will give the reader sufficient information to replicate the airpuff stimulus.

It has been customary to report air pressure in units of pounds per square inch (psi). Although psi is a readily understandable unit of measure in the United States, I would recommend using the pascal $(\mathrm{Pa})$ as a unit of measure. There are three reasons that I recommend $\mathrm{Pa}$ over psi. First, $\mathrm{Pa}$ is the unit of pressure in the International System of Units (SI), and SI units are generally preferred according to the APA Publication Manual (American Psychological Association, 1994). Second, because $1 \mathrm{~Pa}$ equals 1 newton per square meter, where the newton is the SI unit for force, an airpuff pressure reported in $\mathrm{Pa}$ is easily converted into units of force that may be directly related to other units of measure. In contrast, the pound represents force only when multiplied by acceleration due to gravity (say, of the earth). Third, useful pressure values for eliciting the reflex blink may be expressed in integers representing thousands of $\mathrm{Pa}$. For example, pressures of 5-10 kPa are quite effective in eliciting a blink reflex (with a 4-mm orifice, $1 \mathrm{~cm}$ from the skin); however, because all are less than 2 psi, fractional designations are required to differentiate among them. The conversion factors between psi and $\mathrm{kPa}$ are $1 \mathrm{psi}=6.8948 \mathrm{kPa}$, and $1 \mathrm{kPa}=0.1450 \mathrm{psi}$.

Stimulus location. A common location on the subject's face to which the airpuff is presented has been the temple, about $1 \mathrm{~cm}$ lateral to the outer canthus of the eye; the orifice of the air tube is positioned about $1 \mathrm{~cm}$ from the surface of the skin. An airpuff of 5-25 kPa in this location produces a robust blink reflex. This location has been chosen largely because it is near the eye and thus is a similar location to that used with airpuff stimulation in nonhuman animals (Hiraoka \& Shimamura, 1977; R. F. Thompson, 1986) but does not aim the airflow onto the cornea directly. Stimulation in this location probably produces activity in the maxillary branch of the trigeminal nerve (Ongerboer de Visser, 1983). It is also possible to use a location similar to that used for electrical blink elicitation or for glabella region stimulation, although I am not familiar with any studies using such a placement. An investigator should be aware that an airpuff directed at or near the cornea may be an aversive stimulus and, as such, be affectively charged (Haerich, 1994). Therefore, it is probably best to make sure that the orifice is directed so that airflow to the cornea is minimized and to describe the stimulus as a puff of air to the side of the face avoiding any direct mention of its proximity to the eye.
A question that has not been addressed concerns the relative effectiveness of different periorbital presentation locations and contributions of the different branches of the trigeminal system involved in these locations to the production of the blink reflex. The glabellar tap and the typical electrocutaneous stimulus produce activity in the supraorbital branch of the trigeminal nerve. In contrast, an airpuff presented $1 \mathrm{~cm}$ lateral to the outer canthus of the eye probably produces activity in the maxillary branch of the trigeminal nerve (Ongerboer de Visser, 1983). Shahani and Young (1973) have reported regions in which cutaneous stimuli to the face readily elicit a reflex blink. These regions include those served by the supraorbital and maxillary branches of the trigeminal nerve, but not the mandibular branch. Although there is no reason to think that the difference between the temporal and supraorbital locations is important, the question has not been directly examined.

This does not exhaust the locations at which an airpuff can elicit a reliable blink reflex. For example, Kagan and his colleagues have used an airpuff directed at the throat (e.g., Snidman \& Kagan, 1996); however, the stimulus used was about $400 \mathrm{kPa}$, a very intense and intentionally aversive stimulus. There have even been reports that an airpuff directed at the fingertips produces a blink (Garner, Donohue, W. K. Berg, \& Haerich, 1990). While there remains some uncertainty about the mechanism (it might be related to the palmomental reflex), the reflex blinks, while infrequent, are nevertheless reliably more frequent than are blinks in a no-airpuff control condition.

Response measurement. In conditioning paradigms, the presence or absence of the eyeblink conditional on the presentation of the conditioned stimulus is the datum of interest. In his early work, Hilgard (1931; Hilgard \& Campbell, 1936; Hilgard \& Marquis, 1935, 1936) used a photochronographic technique that had been developed by Dodge (1926). In this technique, long paper "eyelashes" are glued to the eyelids of the subject, and a bright light is arranged to shine across the subject's face and focused such that the eyelashes cast a distinct shadow on moving photosensitive paper. The shadows cast by these artificial eyelashes indicate whether and when eyeblinks occurred. The physical blinking of the eyelid has also been measured by attaching one end of a fine piece of thread to the lid and the other to a potentiometer (this technique has been used by Krupa et al., 1993, and R. F. Thompson, 1986 , in work with rabbits, and by Graham, 1975, in work with humans). When the lid moves, the voltage output of the potentiometer changes, and this voltage change may be scored as the eyeblink. Finally, infrared photometry methods that monitor the amount of corneally reflected light (and thus lid closure) are also used (Woodruff-Pak et al., 1996).

Among psychophysiologists, the most common method for measuring the startle-response-related reflex eyeblink is the electromyographic response of the orbicularis oculi muscle by means of miniature electrodes taped to the skin immediately below the eye. With the exception that the re- 
sponse onset latency tends to be about $20-30 \mathrm{msec}$ longer for the airpuff-elicited response, data acquisition and scoring for the airpuff-elicited blink are similar to that of the acoustically elicited response. The methods for electromyographic measurement of this response have been well described elsewhere (W. K. Berg \& Balaban, in press; see also Cacioppo, Tassinary, \& Fridlund, 1990; Fridlund \& Cacioppo, 1986).

\section{Artifacts}

The purpose of the apparatus, such as the one described here, is to produce the reflex blink by airpuff stimulation rather than by or in combination with some other stimulus. Most airpuff systems are subject to a few acoustic artifacts that must be controlled for successful use.

There are three primary sources of acoustic artifacts that are readily identified when using an airpuff system. First, the solenoid valve produces an audible click when it operates. The solution involves isolation and/or insulation. The solenoid may be isolated from the subject by physically locating it in another room. In the LLU system, the tank of air and the solenoid are in a separate room from the subject, with the tube of air passing through the wall via a small conduit to the room where the subject is located. At the University of Florida, W. Keith Berg (personal communication, September 9, 1996) has encased the solenoid within cinder blocks, thoroughly muffling the sound of its operation.

An acoustic artifact is also produced by the flow of air itself-particularly, the "plunk" of the initial air pressure wave. In the LLU system, this artifact is $54 \mathrm{~dB}(\mathrm{~A})$ and $71 \mathrm{~dB}(\mathrm{~A})$ for $10-\mathrm{kPa}$ and $25-\mathrm{kPa}$ airpuffs, respectively. ${ }^{4}$ The third source of acoustic artifacts results from conduction, via the bones of the skull to the cochlea, of the vibrations resulting from the physical impact of the initial wave of air pressure wave to the temple. Both artifacts are reduced by decreasing the intensity of the stimulus. Using air pressures in the range of 5-15 $\mathrm{kPa}$ makes the artifact produced through bone conduction negligible and greatly reduces the intensity of the hiss, while remaining an effective eliciting stimulus. In addition to using a reduced-intensity airpuff, the hiss artifact may be effectively controlled by using a low-intensity white-noise mask presented through headphones (Shortley \& W. K. Berg, 1996).

In addition to these artifacts in the acoustic modality, visual and tactile artifacts may also occur. The greater the stimulus intensity, the more likely the subject is to experience a movement of the cap (visually, tactilely, or both) as the pulse of air travels through the tubing attached to it. Additionally, if any part of the tubing is within the subject's visual field, a visual movement artifact may be experienced. As with the acoustic artifacts, the movement artifact may be controlled by using a lower air pressure.

\section{Conclusion}

The use of airpuffs to elicit the reflex blink represents a useful addition to the repertoire of the investigator inter- ested in human startle modulation. The necessary apparatus may be assembled with relatively small expense and easily integrated into existing stimulus presentation systems. An airpuff system such as is described here is not difficult to use and is efficacious across a number of subject populations, including the very young and the elderly.

\section{REFERENCES}

American Academy of Pediatrics Committee on Environmental Health (1994). Noise pollution: Neonatal aspects. Pediatrics, 54, 476-479.

AmERICAN PSYChOLOGICAL Association (1994). Publication manzal of the American Psychological Association (4th ed.). Washington, DC: Author.

ANTHONY, B. J. (1985). In the blink of an eye: Implications of reflex modification for information processing. In P. K. Ackles, J. R. Jennings, \& M. G. H. Coles (Eds.), Advances in psychophysiology (Vol. 1, pp. 167-218). Greenwich, CT: JAI.

ANTHONY, B. J., \& GRAHAM, F. K. (1983). Evidence for sensory-selective set in young infants. Science, 220, 742-744.

BERG, K. M. (1973), Elicitation of acoustic startle in the human. Unpublished doctoral dissertation, University of Wisconsin, Madison.

BERG, W. K., \& Balaban, M. T. (in press). Startle elicitation: Stimulus parameters, recording techniques, and quantification. In M. E. Dawson, A. M. Schell, \& A. H. Boehmelt (Eds.), Startle modification: Implications for neuroscience, cognitive science, and clinical science. Cambridge: Cambridge University Press.

Blumenthal, T. D., \& BerG, W. K. (1986a). The startle response as an indicator of temporal summation. Perception \& Psychophysics, $\mathbf{4 0}$, 62-68.

Blumenthal, T. D., \& BerG, W. K. (1986b). Stimulus rise time, intensity, and bandwidth effects on acoustic startle amplitude and probability. Psychophysiology, 23, 635-641.

Boelhouwer, A.J. W., Teurlings, R. J. M. A., \& Brunia, C. H. M. (1991). The effect of an acoustic warning stimulus upon the electrically elicited blink reflex in humans. Psychophysiology, 28, 133-139.

Brunia, C. H. M., \& Boelhouwer, A. J. W. (1988). Reflexes as a tool: A window in the central nervous system. In P. K. Ackles, J. R. Jennings, \& M. G. H. Coles (Eds.), Advances in psychophysiology (Vol. 3, pp. 168). Greenwich, CT: JAI.

Caciopro, J. T., Tassinary, L. G., \& Fridlund, A. J. (1990). The skeletomotor system. In J. T. Cacioppo \& L. G. Tassinary (Eds.), Principles of psychophysiology: Physical, social, and inferential elements (pp. 325-384). Cambridge: Cambridge University Press.

Daum, I., Schugens, M. M., Ackermann, H., Lutzenberger, W., Dichgans, J., \& Birbaumer, N. (1993). Classical conditioning after cerebellar lesions in humans. Behavioral Neuroscience, 107, 748756.

DoDGE, R. (1926). A pendulum photochronograph. Journal of Experimental Psychology, 9, 155-161.

Fridlund, A. J., \& CACIOPPO, J. T. (1986). Guidelines for human electromyographic research. Psychophysiology, 23, 567-589.

Garner, E. E., Donohue, R. L., Berg, W. K., \& Haerich, P. (1990). Blinks at your fingertips: A digital-orbicularis oculi reflex? [Abstract] Psychophysiology, 27, S34.

Graham, F. K. (1975). The more or less startling effects of weak prestimulation. Psychophysiology, 12, 238-248.

HaCKLEY, S. A., \& Graham, F. K. (1983). Early selective attention effects on cutaneous and acoustic blink reflexes. Physiological Psychology, 11, 235-242

HACKLEY, S. A., \& GRAHAM, F. K. (1987). Effects of attending selectively to the spatial position of reflex-eliciting and reflex-modulating stimuli. Joumal of Experimental Psychology: Human Perception \& Performance, 13, $411-424$.

HACKLEY, S. A., \& JoHNSON, L. N. (1996). Distinct early and late subcomponents of the photic blink reflex: Response characteristics in patients with retrogeniculate lesions. Psychophysiologv, 33, 239-251. 
HAERICH, P. (1994). Startle reflex modification: Effects of attention vary with emotional valence. Psychological Science, 5, 407-410.

Hilgard, E. R. (1931). Conditioned eyelid reactions to a light stimulus based on the reflex wink to sound. Psychological Monographs, 41, 1-50.

Hilgard, E. R, \& CAMPBell, A. A. (1936). The course of acquisition and retention of conditioned eyelid responses in man. Journal of Experimental Psychology, 19, 227-247.

Hilgard, E. R., \& MARQU1S, D. G. (1935). Acquisition, extinction, and retention of conditioned lid responses to light in dogs. Journal of Comparative Psychology, 19, 29-57.

Hilgard, E. R., \& MARQuis, D. G. (1936). Conditioned eyelid responses in monkeys, with a comparison of dog, monkey, and man. Psychological Monographs, 47, 186-197.

Hiraoka, M., \& Shimamura, M. (1977). Neural mechanisms of the corneal blinking reflex in cats. Brain Research, 125, 265-275.

KruPA, D. J., Thompson, J. K., \& Thompson, R. F. (1993). Localization of a memory trace in the mammalian brain. Science, 260, 989-991.

Landis, C., \& HuNr, W. A. (1939). The startle pattern. New York: Farrar \& Rinehart.

Lang, P. J., Bradley, M. M., \& Cuthbert, B. N. (1990). Emotion, attention, and the startle reflex. Psychological Review, 97, 377-395.

LanG, P. J., Bradlex, M. M., \& Cuthbert, B. N. (1992). A motivational analysis of emotion: Reflex-cortex connections. Psychological Science, 3, 44-49.

ONGERBOER DE VISSER, B. W. (1983). Comparative study of corneal and blink reflex latencies in patients with segmental or with cerebral lesions. In J. E. Desmedt (Ed.), Motor control mechanisms in health and disease (pp. 757-772). New York: Raven.

Shahani, B. T., \& Young, R. R. (1973). Blink reflexes in orbicularis oculi. In J. E. Desmedt (Ed.), New developments in electromyography and clinical neurophysiology (Vol. 3, pp. 641-648). Basel: Karger.

SHORTLEY, B. M., \& BERG, W. K. (1996). Avoiding noise artifacts in airpuff startle stimuli [Abstract]. Psychophysiology, 33, S77.

Snidman, N. \& Kagan, J. (1996). Modulation of the potentiated startle response: The role of temperament [Abstract]. Psychophysiology, 33, 578 .

SPENCE, K. W. (1966). Extinction of the human eyelid CR as a function of presence or absence of the UCS during extinction. Journal of Experimental Psychology, 71, 642-648.

SPENCE, K. W., \& Ross, L. E. (1959). A methodological study of the form and latency of eyelid responses in conditioning. Journal of Experimental Psychology, 58, 376-381.
Thompson, R. F. (1986). The neurobiology of learning and memory. Science, 233, 941-947.

VRana, S. R., Spence, E. L., \& Lang, P. J. (1988). The startle probe response: A new measure of emotion? Journal of Abnormal Psychology, 97, 487-491.

Witvliet, C. V., \& VRANA, S. R. (1996). Emotional imagery and the visual startle reflex: Negative valence and high arousal independently increase magnitudes [Abstract]. Psychophysiology, 33, S91

Woodruff-PaK, D. S., Romano, S., \& PAPKA, M. (1996). Training to criterion in eyeblink classical conditioning in Alzheimer's disease, Down's syndrome with Alzheimer's disease, and healthy elderly. $B e$ havioral Neuroscience, 110, 22-29.

\section{NOTES}

1. The functional life of a tank of air depends on both the number of airpuffs used per subject and the total time the tank is open and air is flowing to the regulator. This is because the regulator, which is designed to maintain a constant pressure, will allow air to leak at a slow rate. Thus, if the valve between the air tank and the regulator is left open over a long weekend, most of the air will have bled off-a situation, unfortunately, familiar at the LLU laboratory.

2. Information on all of the companies listed in this section-Fisher Scientific, Skinner Electric Valves, and Coulbourn Instruments - may be obtained on the Internet by doing a search for the company name and current URL on a search engine such as Yahoo!

3. One reviewer indicated that, in the systems used in their lab, when the solenoid has not been activated in the previous $20-100 \mathrm{sec}$, the delay due to inertia may be increased by up to $3 \mathrm{msec}$. Thus, if intertrial intervals of this range or greater are used, this additional source of delay should be considered as well.

4. This measurement was made with a Quest 2700 sound level meter set to register and hold peak levels of intensity. The regulator was set to 10 - and $25-\mathrm{kPa}$ output. The 4-mm-diameter orifice of the plastic tube was placed $5 \mathrm{~cm}$ from the sound level meter so that the airflow was not directly toward the microphone (i.e., the arrangement was similar to that which would occur between the plastic tube and the ear canal of a subject).

(Manuscript received January 21, 1997; revision accepted for publication July 9,1997 .) 